\title{
Angiotensin-converting enzyme gene DD genotype is associated with increased systolic blood pressure in an Australian Rural Type 2 Diabetic Cohort
}

\author{
Hypertension Research (2013) 36, 381-382; doi:10.1038/hr.2012.195; published online 13 December 2012
}

The renin-angiotensin system is an important autocrine and paracrine system that influences large and small vessel function. In hypertensive patients, there is significant evidence to suggest that reduced arterial compliance is due to activation of the local renin-angiotensin system. ${ }^{1}$ Gene regulation of renin-angiotensin system activity through angiotensin-converting enzyme gene $(A C E)$ polymorphisms likely has a role in the development of hypertension. ACE polymorphism refers to the presence (insertion, denoted I) or absence (deletion, denoted D) of a 287-bp sequence of DNA in intron 16 of the ACE gene (rs4340). ${ }^{2}$ Presence of the D allele is associated with higher levels of circulating and tissue ACE and is associated with increased arterial stiffness. ${ }^{3}$ Many studies investigating the effects of the ACE polymorphisms on systolic blood pressure
(SBP) have been inconclusive in heterogeneous ethnic origin populations, but not so in some rural population studies. ${ }^{4}$ Based on an informatics search in Pubmed with combinational search terms ('rural' 'diabetes' 'ACE gene', 'Caucasian'), associations between the ACE gene, systolic pressure and type 2 Diabetes Mellitus (T2DM) have not been evaluated in a Caucasian rural environment. The aim of our study was to examine the effects of ACE I/D polymorphism on SBP in an Australian rural Caucasian T2DM population compared with age-matched controls.

Human ethics clearance was obtained from Charles Sturt University, as well as written informed consent from the patients involved in the present study. ${ }^{5}$ The study group was from a well-characterized New South Wales rural cohort consisting of type 2 adult diabetics $(n=43)$ and controls $(n=93)$.
This cohort was derived from the Charles Sturt University Diabetes Screening Research Initiative. ${ }^{5}$ Two BP readings at the upper arm were taken with the patient in a supine position, after resting for $30 \mathrm{~min}$, and the average recorded. Following BP determination, a blood sample was obtained for genomic DNA extraction. DNA was extracted from frozen blood samples using the QIAamp DA blood mini kit (Qiagen $\mathrm{GmbH}$, Hilden, Germany) according to the manufacturer's instructions. The extracted DNA was then genotyped for the ACE polymorphism using the triple primer method (Evans, 1994) and electrophoresis using a $6 \%$ polyacrylamide gel. Demographics according to ACE polymorphism for controls and T2DM are shown in Table 1a. All statistical tests were carried out using analysis of variance followed by a Tukey

Table 1a Demographics of cohort according to genotype and diabetic status

\begin{tabular}{|c|c|c|c|c|c|c|}
\hline \multirow[b]{2}{*}{ Genotype } & \multicolumn{3}{|c|}{$T 2 D M(n=43)$} & \multicolumn{3}{|c|}{ Controls $(\mathrm{n}=93)$} \\
\hline & $D D(\mathrm{n}=9)$ & $I D(\mathrm{n}=25)$ & $/ /(\mathrm{n}=9)$ & $D D(\mathrm{n}=20)$ & $I D(\mathrm{n}=49)$ & $/ /(\mathrm{n}=24)$ \\
\hline Age (years) & $67.6 \pm 7.0$ & $68.3 \pm 7.6$ & $67.3 \pm 7.9$ & $67.2 \pm 10.2$ & $65.9 \pm 10.9$ & $64.0 \pm 10.0$ \\
\hline Male/Female & $2 / 7$ & $12 / 13$ & $4 / 5$ & $9 / 11$ & $20 / 29$ & $8 / 16$ \\
\hline Duration of diabetes & $12.9 \pm 7.9$ & $11.4 \pm 5.4$ & $13.2 \pm 6.7$ & $\mathrm{~N} / \mathrm{A}$ & $\mathrm{N} / \mathrm{A}$ & $\mathrm{N} / \mathrm{A}$ \\
\hline Hypertension (\%) & 88.9 & 76.0 & 77.8 & 35.0 & 36.7 & 37.5 \\
\hline Duration of hypertension (years) & $25.0 \pm 13.2$ & $14.7 \pm 11.5$ & $21.0 \pm 8.8$ & $11.7 \pm 8.4$ & $10.1 \pm 8.3$ & $12.6 \pm 13.8$ \\
\hline Current smoker (\%) & 0.0 & 4.0 & 0.0 & 0.0 & 0.0 & 0.0 \\
\hline Alcohol (\%) & 11.1 & 8.0 & 0.0 & 0.0 & 8.2 & 4.2 \\
\hline BMI & $31.4 \pm 8.8$ & $29.7 \pm 5.4$ & $29.1 \pm 3.3$ & $26.7 \pm 4.5$ & $27.5 \pm 4.8$ & $26.8 \pm 4.2$ \\
\hline Waist circumference $(\mathrm{cm})$ & $107.1 \pm 18.0$ & $104.1 \pm 16.7$ & $101.3 \pm 11.4$ & $94.2 \pm 9.9$ & $96.3 \pm 12.9$ & $93.5 \pm 12.8$ \\
\hline $\mathrm{HR}$ & $68.7 \pm 9.8$ & $69.5 \pm 11.2$ & $71.0 \pm 10.4$ & $64.1 \pm 9.4$ & $65.8 \pm 11.3$ & $61.1 \pm 7.2$ \\
\hline $\mathrm{SBP}(\mathrm{mm} \mathrm{Hg})$ & $146.8 \pm 32.8$ & $124.7 \pm 14.2$ & $125.6 \pm 7.5$ & $121.9 \pm 15.8$ & $125.0 \pm 16.9$ & $127.8 \pm 22.0$ \\
\hline DBP (mm Hg) & $77.3 \pm 9.8$ & $73.8 \pm 8.7$ & $71.7 \pm 6.6$ & $73.0 \pm 5.2$ & $73.1 \pm 9.2$ & $75.1 \pm 8.4$ \\
\hline eGFR $\left(\mathrm{ml} \mathrm{min}^{-1}\right)$ & $77.0 \pm 14.5$ & $76.3 \pm 15.2$ & $70.9 \pm 21.2$ & $76.0 \pm 15.0$ & $79.4 \pm 13.5$ & $85.0 \pm 7.4$ \\
\hline $\mathrm{HbAlc}(\%)$ & $6.9 \pm 0.6$ & $6.6 \pm 0.9$ & $7.3 \pm 1.1$ & $5.5 \pm 0.3$ & $5.6 \pm 0.3$ & $5.7 \pm 0.8$ \\
\hline Screening glucose $\left(\mathrm{mmol}^{-1}\right)$ & $7.8 \pm 9.8$ & $7.4 \pm 1.8$ & $9.5 \pm 1.1$ & $5.4 \pm 0.4$ & $5.6 \pm 0.7$ & $5.8 \pm 1.5$ \\
\hline
\end{tabular}

Abbreviations: BMI, body mass index; DBP, diastolic blood pressure; eGFR, estimated glomerular filtration rate; HbA1c, Glycated Haemoglobin; HR, heart rate; T2DM, type 2 Diabetes Mellitus; $\mathrm{SBP}$, systolic blood pressure. 
Table $1 \mathrm{~b}$ Frequency of hypertensive medications

\begin{tabular}{|c|c|c|c|c|c|c|}
\hline \multirow[b]{2}{*}{ Genotype } & \multicolumn{3}{|c|}{$T 2 D M(n=43)$} & \multicolumn{3}{|c|}{ Controls $(n=93)$} \\
\hline & $D D(\mathrm{n}=9)$ & $I D(n=25)$ & $/ /(n=9)$ & $D D(\mathrm{n}=20)$ & $I D(n=49)$ & $/ I(n=24)$ \\
\hline *ACE I (\%) & 33.3 & 20.0 & 33.3 & 15.0 & 14.3 & 4.2 \\
\hline${ }^{*} \beta$-Blocker (\%) & 33.3 & 40.0 & 33.3 & 15.0 & 10.2 & 8.3 \\
\hline${ }^{*} \mathrm{CCB}(\%)$ & 11.1 & 12.0 & 33.3 & 5.0 & 8.2 & 4.2 \\
\hline *Diuretic (\%) & 11.1 & 16.0 & 22.2 & 5.0 & 8.2 & 4.2 \\
\hline ARB (\%) & 33.3 & 44.0 & 44.4 & 15.0 & 16.3 & 25.0 \\
\hline
\end{tabular}

Abbreviations: ACE, angiotensin-converting enzyme gene; ARB, angiotensin receptor blockers; CCB, calcium channel blocker; T2DM, type 2 diabetes mellitus.

${ }^{*} P<0.05$.

post hoc test. Demographics are presented as $\%$ differences, means $+/-$ s.d.

The ACE genotypes are in HardyWeinberg equilibrium in both T2DM and control groups. The distributions of alleles D and I are not significantly different in T2DM and control groups (50 and $50 \%$ vs. $47.8 \%$ and $52.2 \%)$. We observed that the T2DM $A C E$ DD genotype had a significantly higher SBP $(P<0.03)$ compared with the ID and II T2DM subgroups. When we compared SBP on the basis of the ACE DD genotype for the T2DM subgroup vs. controls $(146.8 \pm 32.8$ vs. $121.9 \pm 15.8$, respectively) there was a significant difference $(P<0.05)$. When we stratified controls on the basis of ACE genotype (DD vs. ID vs. II;) we did not observe any significant mean SBP differences $(P=\mathrm{NS}$, non significant). Our findings show that there were no significant differences in mean SBP between T2DM and controls $(P=\mathrm{NS})$.

The potential for use of antihypertensive medication in the ACE DD T2DM subgroup to influence the findings was explored. Individual classes of antihypertensive medication based on the proportions of self reported use did not significantly differ across T2DM subgroups based on genotype $(P=$ NS; Table $1 \mathrm{~b})$.

Thus, our significant finding was that the $A C E$ DD genotype was associated with increased SBP in this small cohort. This suggests a recessive genetic model as there was no significant difference between T2DM subjects with one D allele and those without $\mathrm{D}$ allele. Overall our finding is interesting because in a Caucasian rural environment an association ACE DD genotype is found with SBP in T2DM patients, but not age-matched controls. The development of hypertension in the presence or absence of diabetes may result from different genetic and environmental factors, implying that pathogenic mechanisms for hypertension may differ between diabetic and non-diabetic populations. ${ }^{6,7}$

Our study indicates an inherent advantage of working with rural populations where there is little migration and ethnic origin is more defined (European ancestry), thus permitting statistical significance to be reached in smaller pilot sample size populations. Additionally, we observed that our rural study T2DM population had a lower frequency for ACE inhibitor use compared with urban populations (unpublished observations), possibly allowing for a greater ability to find $A C E$ gene effects. The mean age of our diabetic cohort was 68 years and similarly 66 years for controls. It is well-known that there is a late fall in diastolic BP after age 60 years, associated with a continual rise in SBP, consistent with increased large artery stiffness. $^{8}$ Increased SBP in our T2DM $A C E / D D$ population is likely to be associated with endothelial dysfunction. For example, the $A C E / D D$ genotype has been previously been shown to be associated with hemostasis balance disturbances and endothelial damage. ${ }^{9}$ Indeed higher SBP prevalence in relation to aging likely advances endothelial dysfunction associated with aging through an increase in oxidative stress. ${ }^{10}$ Oxidative stress would be particularly higher in T2DM.

In summary, higher SBP, left untreated, may accelerate large artery stiffness and, thus, perpetuate a vicious cycle. ${ }^{8}$ In particular this vicious cycle may be relevant to our aging T2DM patients who carry the ACE DD genotype with high or borderline normal SBP, and are being undertreated with ACE inhibitors or angiotensin receptor blockers. ${ }^{11}$

\section{CONFLICT OF INTEREST}

The authors declare no conflict interest.

Ethan $\mathrm{Ng}^{1}$, Yaxin $\mathrm{Lu}^{1}$, Brett Hambly ${ }^{1}$, Herbert F Jelinek ${ }^{2}$, Bing $\mathrm{Yu}^{3}$, Slade Matthews $^{4}$ and Craig S McLachlan ${ }^{5}$

${ }^{1}$ Discipline of Pathology, University of Sydney, Camperdown, New South Wales, Australia; ${ }^{2}$ Research in Complex Systems, Charles Sturt University, Albury, New South Wales, Australia; ${ }^{3}$ Department of Molecular and Clinical Genetics, Royal Prince Alfred

Hospital, Sydney, New South Wales, Australia; ${ }^{4}$ Discipline of Pharmacology, University of Sydney, Camperdown, New South Wales, Australia and ${ }^{5}$ Rural Clinical School, University of New South Wales, Sydney, New South Wales, Australia E-mail: reperfusion@hotmail.com

1 Dzau VJ, Safar ME. Large conduit arteries in hypertension: role of the vascular renin-angiotensin system. Circulation 1988; 77: 947-954.

2 Gayagay G, Yu B, Hambly B, Boston T, Hahn A, Celermajer DS, Trent RJ. Elite endurance athletes and the ACE I allele-the role of genes in athletic performance. Hum Genet 1998; 103: 48-50.

3 Yasmin O'Shaughnessy KM. Genetics of arterial structure and function: towards new biomarkers for aortic stiffness? Clin Sci (Lond) 2008; 114: 661-677.

4 Gupta S, Agrawal BK, Goel RK, Sehajpal PK. Angiotensin-converting enzyme gene polymorphism in hypertensive rural population of Haryana, India. J Emerg Trauma Shock 2009; 2: 150-154.

5 White F, Wang L, Jelinek HF. Management of hypertension in patients with diabetes mellitus. Exp Clin Cardiol 2010; 15: 5-8.

6 Jarrett RJ. Hypertension in diabetic patients and differences between insulin-dependent diabetes mellitus and non-insulin-dependent diabetes mellitus. Am J Kidney Dis 1989; 13: 14-16.

7 Su W, Guo Z, Randall DC, Cassis L, Brown DR, Gong MC. Hypertension and disrupted blood pressure circadian rhythm in type 2 diabetic $\mathrm{db} / \mathrm{db}$ mice. $A m \mathrm{~J}$ Physiol Heart Circ Physiol 2008; 295: H1634-H1641.

8 Franklin SS, Gustin 4th W, Wong ND, Larson MG Weber MA, Kannel WB, Levy D. Hemodynamic patterns of age-related changes in blood pressure. The Framingham Heart Study. Circulation 1997; 96: 308-315.

9 Makris TK, Stavroulakis GA, Dafni UG, Gialeraki AE Krespi PG, Hatzizacharias AN, Tsoukala CG, Vythoulkas JS, Kyriakidis MK. ACE/DD genotype is associated with hemostasis balance disturbances reflecting hypercoagulability and endothelial dysfunction in patients with untreated hypertension. Am Heart J 2000; 140: 760-765.

10 Higashi Y, Kihara Y, Noma K. Endothelial dysfunction and hypertension in aging. Hypertens Res 2012; 35: 1039-1047.

11 Geng DF, Jin DM, Wu W, Xu Y, Wang JF. Angiotensin receptor blockers for prevention of new-onset type 2 diabetes: a meta-analysis of 59,862 patients. Int J Cardiol 2012; 155: 236-242. 